\title{
QUANTITATIVE PREDICTION OF SAND DISCHARGE INTO SUBMARINE CANYON OFF MORITO RIVER ON SEISHO COAST, JAPAN
}

\author{
Kou Furuike', Takaaki Uda ${ }^{2}$, Masumi Serizawa ${ }^{1}$, \\ Toshiro San-nami ${ }^{1}$ and Toshinori Ishikawa ${ }^{2}$
}

\begin{abstract}
On the Seisho coast, submarine canyons have developed very close to the shoreline and the discharge of fluvial sediment of the Sakawa River into the submarine canyons has been reported, resulting in the net loss of sand into the offshore zone. The beach topography under dynamically equilibrium conditions owing to the sediment supply from the river and the sand loss into the submarine canyons during several thousand years was reproduced using the contour-line-change model considering the grain size composition. Long-term beach changes around the submarine canyons were accurately predicted and the effect of beach nourishment using a mixture of fine and coarse materials was investigated.
\end{abstract}

Keywords: submarine canyon; beach changes; long-term prediction; contour-line-change model; Seisho coast

\section{INTRODUCTION}

On the Seisho coast, which faces Sagami Bay, as shown in Fig. 1, submarine canyons have developed very close to the shoreline and the discharge of fluvial sediment into the submarine canyons has been reported, resulting in the net loss of sand into the offshore zone. A fluvial fan has been formed by the abundant sediment supplied from the Sakawa River flowing into this coast, and part of the sediment is considered to have directly sunk into the offshore zone. Since the dam construction and extensive riverbed excavation in the $1970 \mathrm{~s}$, beach erosion has been severe on this coast, and urgent measures are now required to protect the coast. To accomplish this aim, beach changes and offshore sand transport through the submarine canyons must be predicted. Because the sediment supply from the Sakawa River has continued for at least several thousand years, i.e., since the sea level reached the present level, the beach topography is considered to have reached a dynamically equilibrium condition,

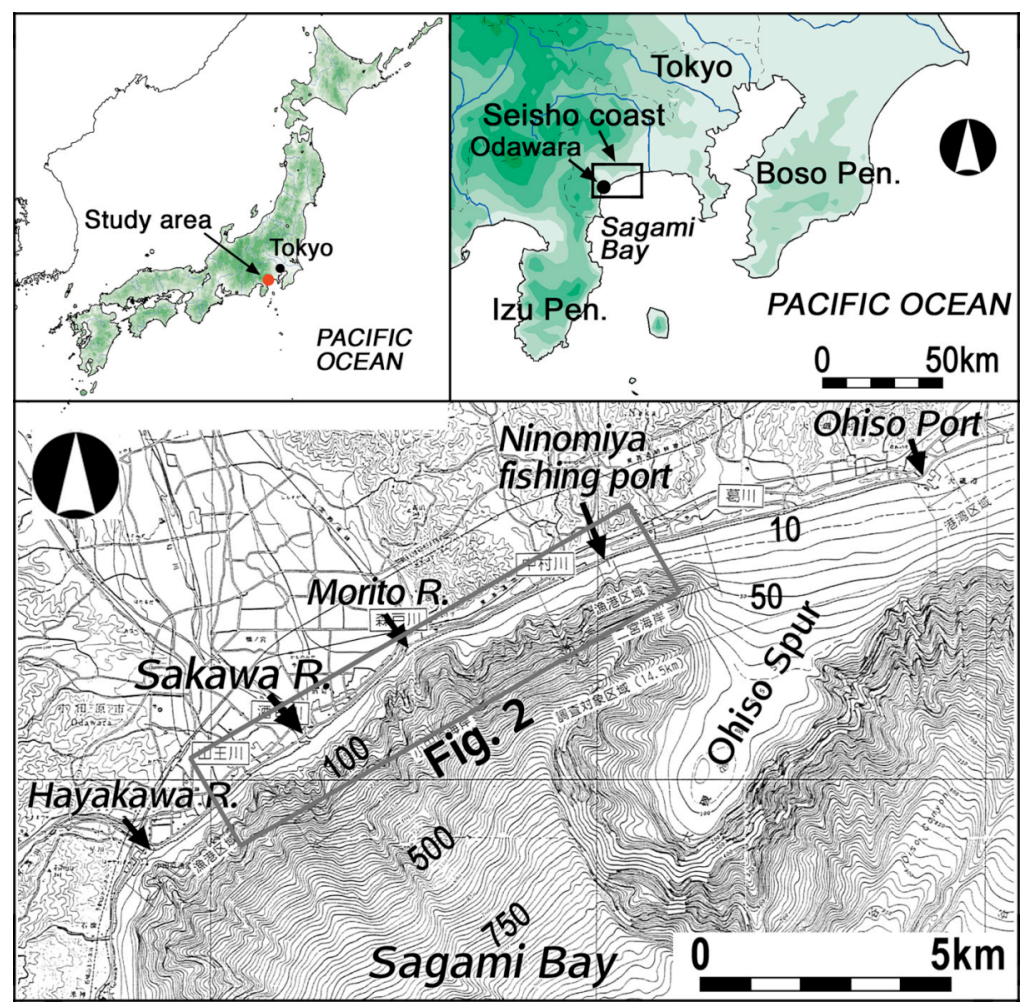

Figure 1. Location of Seisho coast in Sagami Bay.

\footnotetext{
${ }^{1}$ Coastal Engineering Laboratory Co., Ltd., 1-22-301 Wakaba, Shinjuku, Tokyo 160-0011, Japan

${ }^{2}$ Public Works Research Center, 1-6-4 Taito, Taito, Tokyo 110-0016, Japan
} 
in which the sediment discharged from the river and longshore sand transport away from the river mouth balance each other. In addition, because the sediment supplied from the Sakawa River is a mixture of sand with various grain sizes, their sorting effect should be considered. In this study, the contour-line-change model considering the grain size composition is applied to solve the problem.

\section{FUNDAMENTAL REQUIREMENTS OF STUDY}

In the area under study, a large amount of sediment has been supplied from the Sakawa River with a steep river bed slope, while forming a coastal fluvial fan. Such sediment had been transported by eastward longshore sand transport along with the sorting by waves. During this process, almost all parts of the sediment were discharged into the submarine canyons, and only a part of the sediment was able to pass through the canyon head. To accurately predict these phenomena, the following conditions must be considered.

1. Since the Sakawa River with a steep slope has formed a coastal fluvial fan, the sediment may directly discharge into the deep sea offshore of the river mouth, when a sufficient volume of sediment was supplied to the coast, and therefore, the steep slope is considered to remain intact in the offshore seabed. In the numerical simulation, such mechanism of beach changes must be explained.

2. Offshore sand movement and the resulting loss of sand via the submarine canyon offshore of the Morito River mouth must be explained.

3. Sand supply from the Sakawa River has continued for several thousand years since the sea level reached the present level. Therefore, the fact that the beach reached a dynamically equilibrium condition in the long term under the conditions that sand supplied from the river was transported at the same rate by eastward longshore sand transport must be explained.

4. Then, the decrease in sand supply due to excess sand mining on the river bed after World War II and the effect of construction of various coastal structures must be evaluated.

5. The sediment supplied from the Sakawa River has a composition of gravel, sand and silt. Therefore, the movement and deposition of each component must be predicted along with the sorting of the material.

\section{BATHYMETRY AND CONTENT OF EACH GRAIN SIZE}

Figure 2 shows the bathymetry of the Seisho coast measured in 1990, where the seabed slope is as steep as 1/10 and submarine canyons have developed very close to the shoreline. In particular, a large submarine canyon develops offshore of the Morito River mouth. The Sakawa River delta protrudes west of this submarine canyon and sand supplied from the river has mainly been transported by eastward longshore sand transport. Figure 3 shows the longitudinal profiles, depth distributions of the median diameter $d_{50}$ and the composition of seabed material measured in 2008 along transect No. 3, immediately west of the Sakawa River mouth, and transect No. 33, across the submarine canyon, as shown in Fig. 2.

Along transect No. 3, $d_{50}$ is larger than $10 \mathrm{~mm}$ in the zone shallower than $-3 \mathrm{~m}$ and gravel is deposited on the shoreline, whereas $d_{50}$ is smaller than $0.3 \mathrm{~mm}$ in the zone deeper than $-5 \mathrm{~m}$. In contrast, along transect No. 33, the seabed slope is as steep as $1 / 7$ and gravel is deposited up to the depth of -10 $\mathrm{m}$. The same characteristics can be seen from the distribution of composition. Gravel is selectively deposited near the shoreline of transect No. 3 far from the submarine canyon, whereas the offshore bed is covered with fine sand $(0.075-0.25 \mathrm{~mm})$, medium sand $(0.25-0.425 \mathrm{~mm})$ and coarse sand $(0.425-2.0$ $\mathrm{mm})$. In addition, no silt can be found along both transects.

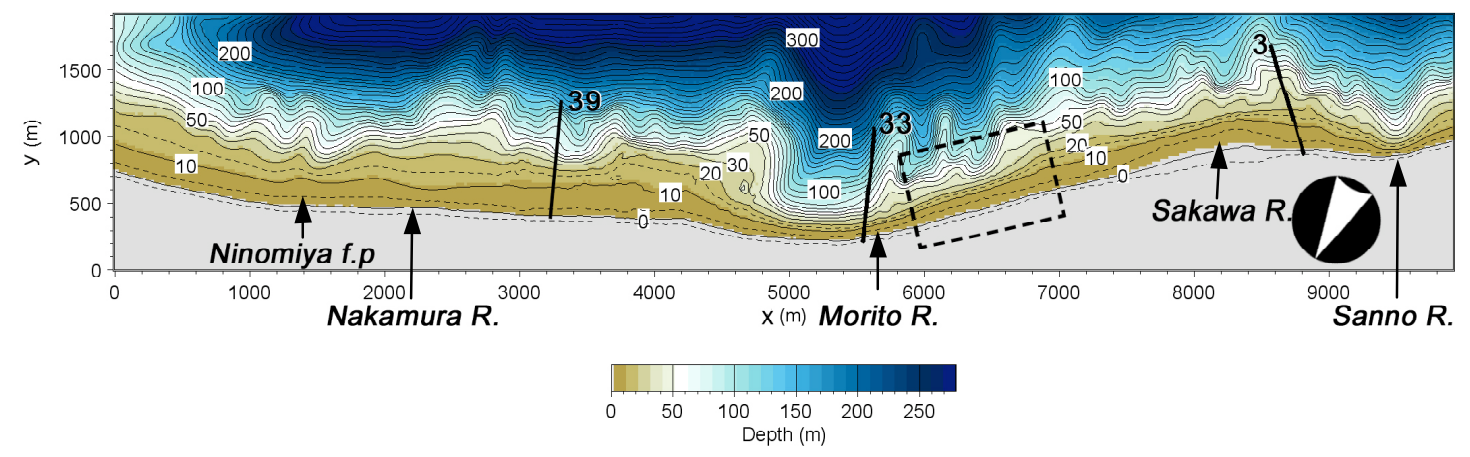

Figure 2. Bathymetry of Seisho coast measured in 1990. 

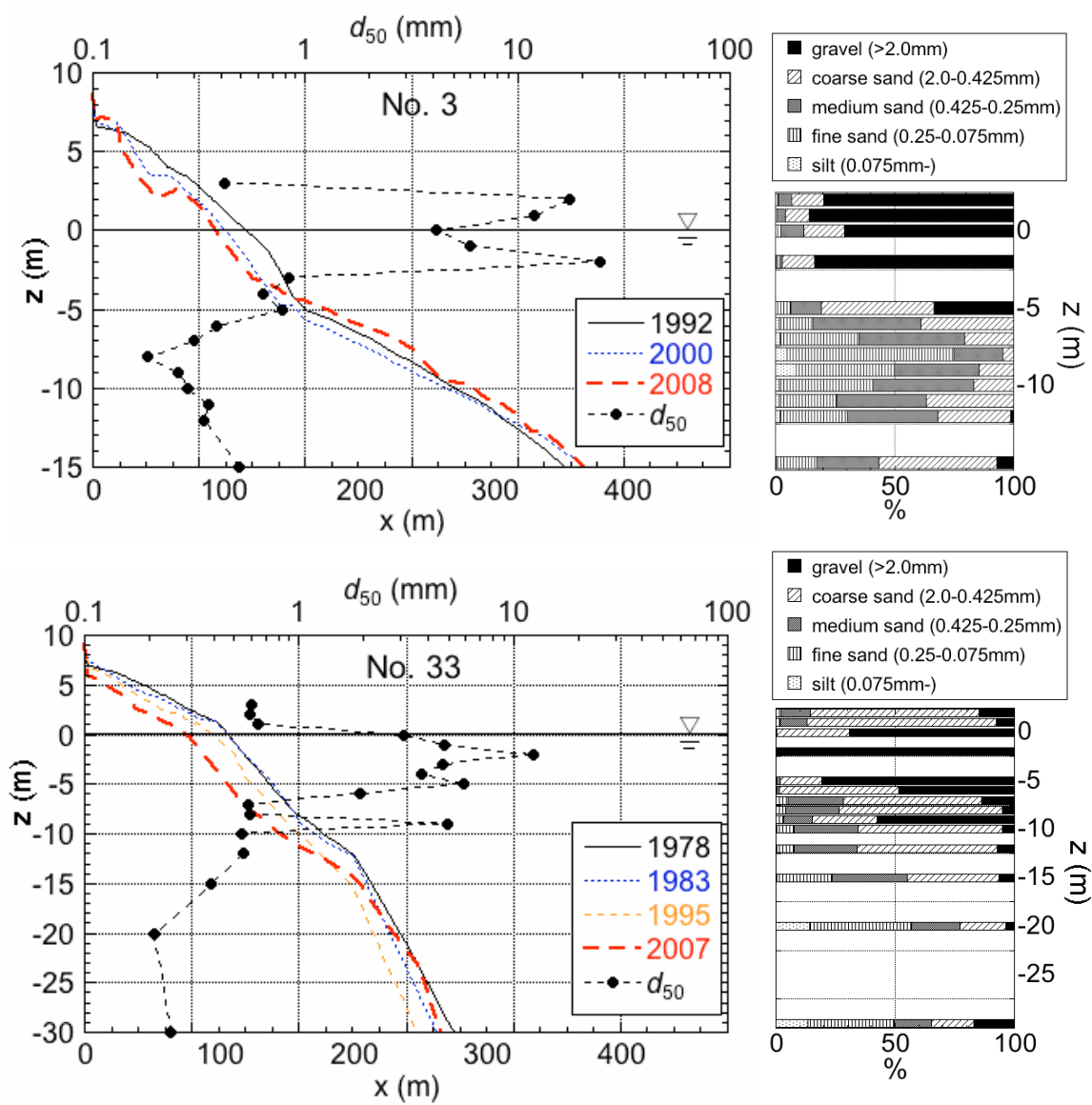

Figure 3. Longitudinal profiles, depth distributions of median diameter $\left(d_{50}\right)$ and composition of seabed material measured in 2008 along transects No. 3 and No. 33.

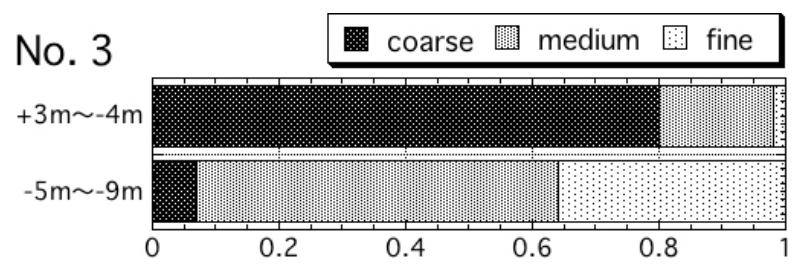

No. 33

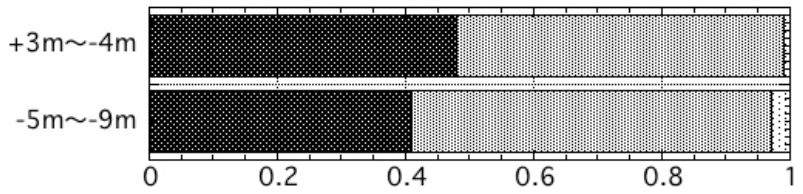

No. 39

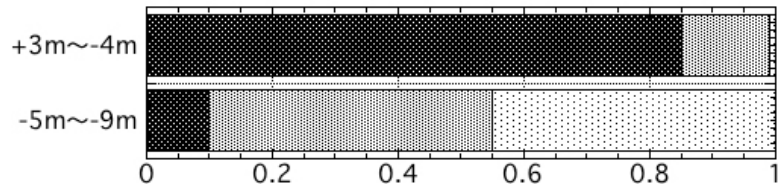

Figure 4. Mean contents of fine-, medium- and coarse-size materials with grain size ranges of $d \leq 0.25 \mathrm{~mm}$, $0.25 \leq d \leq 2 \mathrm{~mm}$ and $2 \mathrm{~mm} \leq d$, respectively. 
Since there is a change in the slope located at a depth of approximately $-5 \mathrm{~m}$ in the longitudinal profile along transect No. 3, as shown in Fig. 3, the depth zone can be separated into two zones with depths of less than and larger than $-5 \mathrm{~m}$. Using the data in the depth zones between $+3 \mathrm{~m}$ and $-4 \mathrm{~m}$ and between $-5 \mathrm{~m}$ and $-9 \mathrm{~m}$, the mean contents of fine-, medium- and coarse-size materials with grain size ranges of $\mathrm{d} \leq 0.25 \mathrm{~mm}, 0.25 \leq \mathrm{d} \leq 2 \mathrm{~mm}$ and $2 \mathrm{~mm} \leq \mathrm{d}$, respectively, were determined, as shown in Fig. 4 . When not only the results along transect No. 3, but also those measured along transect No. 39 located $0.5 \mathrm{~km}$ west of the Nakamura River are considered, the content of coarse-size material reaches over 0.80 in the depth zone between $+3 \mathrm{~m}$ and $-4 \mathrm{~m}$, whereas the contents of fine- and medium-size materials reach over 0.90 in the offshore zone, showing a marked asymmetry with the depth. In contrast, along transect No. 33 through the submarine canyon, medium- and coarse-size materials are present at half-and-half regardless of the water depth, implying that medium- and coarse-size materials were transported and deposited up to the deeper zone in the submarine canyon compared with the conditions along transects No. 3 and No. 39.

\section{NUMERICAL MODEL}

A numerical model developed on the basis of the contour-line-change model proposed by Serizawa et al. (2003) was used. Let the $x$ - and $z$-axes be the longshore distance and the depth, respectively, and $Y$ is the offshore distance to a specific contour line. The cross-shore transport of sand composed of mixed grain sizes can be modeled by expanding the concept of single grain size. The sorting of grain size populations, such as those of fine sand, medium and coarse sand, and gravel, can be modeled by introducing the equilibrium slope angle $\beta_{c}{ }^{(k)}$ which corresponds to each grain size population $k$. In this case, a grain size population is assumed to have a single equilibrium beach slope with a characteristic grain size $d^{(k)}$, for example, the median diameter of the grain size population.

By assuming that the mobility of sand of each grain size population by cross-shore movement under the same wave conditions is the same as that of longshore sand transport, the coefficient of the sediment transport rate according to the grain size $d^{(k)}$, which was given by Kamphius et al. (1986) and Kumada et al. (2003), is introduced. Furthermore, assuming that the ratio of the exposed area of each grain size population to the entire sea bottom area is equal to the content of each size population in the exchange layer $\mu^{(k)}$ (where $k=1,2, \cdots \cdot, N$ ), the cross-shore sand transport rate of each grain size population $q_{z}^{(k)}$ is derived by a method similar to that of Uda et al. (2004).

\section{Cross-shore sand transport}

$$
\begin{aligned}
& q_{z}^{(k)}=\mu^{(k)} \cdot \varepsilon_{z}(z) \cdot \gamma \cdot K_{1}^{(k)} \cdot\left(E C_{g}\right)_{b} \cos ^{2} \alpha_{b s} \sin \bar{\beta} \cdot\left(\cot \beta / \cot \beta_{c}^{(k)}-1\right) \\
& ; k=1,2, \ldots, N \\
& K_{1}^{(k)}=\frac{A}{\sqrt{d^{(k)}}} \\
& \cot \beta=-\partial Y / \partial z \\
& \varepsilon_{z}(z)= \begin{cases}\left(2 / h_{C}^{3}\right)\left(h_{C} / 2-z\right)\left(z+h_{C}\right)^{2}, & -h_{C} \leq z \leq h_{R} \\
0, & z \leq-h_{C}, z \geq h_{R}\end{cases}
\end{aligned}
$$

Here, $q_{z}^{(k)}(k=1, \cdots, N)$ is the cross-shore sand transport per unit length in the longshore direction for each grain size population, $\mu^{(k)}$ is the content of each grain size population $(k)$ in the exchange layer of sand, $\varepsilon_{z}(z)$ is assumed to be equivalent to the depth distribution of the longshore sand transport $\varepsilon_{x}(z)$ given by Uda and Kawano (1996), and $d^{(k)}$ is a typical grain size of the grain size population. $A$ is a coefficient that depends on the physical conditions of the beach, $d^{(k)}$ in Eq. (2) has a unit of mm, $K_{1}{ }^{(k)}$ is the coefficient of longshore sand transport, $\gamma$ is the ratio of the coefficient of cross-shore sand transport to the coefficient of longshore sand transport, and expresses the mobility of cross-shore sand transport relative to that of longshore sand transport, $\alpha_{b s}$ is the angle between the wave crest line at the breaking point and each contour line, and $\beta$ is the beach slope angle at each contour line. $\bar{\beta}$ is the average beach slope angle between the berm height $h_{R}$ and the depth of closure $h_{c}$, and $\beta_{c}{ }^{(k)}$ is the equilibrium beach slope angle. When the beach slope becomes steeper than the angle of repose of sand, sand is transported offshore by gravity. By this procedure, we can calculate the formation of a scarp in a zone larger than the berm height $h_{R}$ and the sinking of sand in a zone larger than the depth of closure $h_{c}$. 
$\underline{\text { Longshore sand transport }}$

$$
\begin{aligned}
& q_{x}^{(k)}=\mu^{(k)} \cdot \varepsilon_{x}(z) \cdot K_{1}^{(k)} \cdot\left(E C_{g}\right)_{b} \cdot \\
& \left(\cos \alpha_{b s} \sin \alpha_{b s}-\xi \frac{1}{\tan \beta} \cdot \cos \alpha_{b s} \cdot \frac{\partial H_{b}}{\partial x}\right)
\end{aligned}
$$

Here, $q_{x}^{(k)}(k=1, \cdots, N)$ is the longshore sand transport per unit depth for each grain size population, $\varepsilon_{x}(z)$ is the depth distribution of longshore sand transport, and $\xi$ is the constant given by $K_{2}{ }^{(k)} / K_{1}{ }^{(k)}$, which depends on the physical conditions of the beach, where $K_{2}{ }^{(k)}$ is a function of $K_{1}{ }^{(k)}$ and is equivalent to the coefficient of Ozasa and Brampton (1980). $\tan \beta$ is the beach slope in the surf zone and $H_{b}$ is the breaker height.

Mass conservation for each grain size

$$
\begin{aligned}
\frac{\partial y^{(k)}}{\partial t} & =-\frac{\partial q_{x}^{(k)}}{\partial x}-\frac{\partial q_{z}^{(k)}}{\partial z} \\
; k & =1,2, \ldots, N
\end{aligned}
$$

The total contour line change at a certain position is determined by the summation of the contour line changes of all grain size populations at that position.

$$
\frac{\partial Y}{\partial t}=\sum_{k=1}^{N} \frac{\partial y^{(k)}}{\partial t}
$$

Change in content of each grain size population

$$
\begin{aligned}
\frac{\partial \mu^{(k)}}{\partial t} & =\frac{1}{B}\left\{\frac{\partial y^{(k)}}{\partial t}-\frac{\partial Y}{\partial t} \cdot \mu^{(k)}\right\} \\
; k & =1,2, \ldots, N
\end{aligned}
$$

The content of each grain size population in the new exchange layer formed during erosion is expressed as

$$
\frac{\partial \mu^{(k)}}{\partial t}=\frac{1}{B}\left\{\frac{\partial y^{(k)}}{\partial t}-\frac{\partial Y}{\partial t} \cdot \mu_{B}^{(k)}\right\}
$$

where $\mu_{B}^{(k)}$ is the content of each grain size population on the sandy beach landward of the initial exchange layer. The width $B$ of the exchange layer is determined with reference to the mixing depth reported by Kraus (1985). The above-mentioned equations were solved simultaneously.

\section{CALCULATION CONDITIONS}

The wave diffraction effect of the coastal structures was calculated using the angular spreading method for irregular waves (Sakai et al., 2006). Table 1 shows the calculation conditions. The calculation domain is the 8 -km-long coast east of the Sakawa River mouth. In the calculation, the bathymetry in 1947, which was under the natural conditions, and the changes until 2007 after dam construction and riverbed excavation had been carried out, were reproduced. The beach changes when no measures were taken were predicted in Case 1, and in Cases 2, 3 and 4, the effect of beach nourishment using coarse- and fine-size materials and their mixture were predicted, respectively.

For the incident wave conditions, the energy-mean wave height measured between 1988 and 2008 $\left(H_{1 / 3}=0.83 \mathrm{~m}\right.$ and $\left.T=6.1 \mathrm{~s}\right)$ at Hiratsuka observatory $10 \mathrm{~km}$ east of the study area was used along with the wave direction from $\mathrm{S} 17^{\circ} \mathrm{E}$ determined as the direction normal to the shoreline downcoast of the Ninomiya fishing port. The mesh size is $100 \mathrm{~m}$ and the time interval is $100 \mathrm{~h}$ so that one year becomes 87.6 steps.

To reproduce the bathymetry in 1947 when the beach was under dynamic equilibrium condition, the calculation was carried out for $2 \times 10^{5}$ steps (2280 years) to obtain the dynamically equilibrium bathymetry after a sufficiently long time given the initial beach topography, as shown in Fig. 2. By using the reproduced topography in 1947, the bathymetry in 2007 was predicted, and then, the 
bathymetry after 10 years was predicted. The equilibrium slope is assumed to be $\tan \beta=1 / 20$ (fine-size material: $d \leq 0.25 \mathrm{~mm}$ ), $1 / 10$ (medium-size material: $0.25 \leq d \leq 2 \mathrm{~mm}$ ) or $1 / 7$ (coarse-size material: $2 \mathrm{~mm} \leq$ d) on the basis of the measured values.

For the boundary conditions, longshore sand transport was estimated on the basis of the shoreline changes between 1930 and 1981 determined by Uda and Yano (1987) using old maps and aerial photographs. Because the area of the river delta that eroded during the period is $8.0 \times 10^{5} \mathrm{~m}^{2}$, the eroded volume becomes $6.6 \times 10^{6} \mathrm{~m}^{3}$ by multiplying the area by the characteristic height of beach changes of $8.2 \mathrm{~m}$ on this coast. Hence, the rate of eastward longshore sand transport becomes $1.8 \times 10^{5} \mathrm{~m}^{3} / \mathrm{yr}$ upon dividing the decrease in the volume of sand by the elapsed time, because sand supply from the river is approximately in equilibrium with the eastward longshore sand transport. Finally, sediment supply from the Sakawa River was assumed to be approximately $2 \times 10^{5} \mathrm{~m}^{3} / \mathrm{yr}$ under the natural conditions.

\section{REPRODUCTION OF DYNAMICALLY EQUILIBRIUM BEACH}

First, sediment supply from the Sakawa River was assumed to be $1.0 \times 10^{5} \mathrm{~m}^{3} / \mathrm{yr}$ as a minimum level, and the sediment supply of each grain size population was calculated by multiplying this sediment yield by the content of each grain size population of $\mu_{1}=0.06, \mu_{2}=0.56$ and $\mu_{3}=0.38$, taking into account the composition of of the river mouth, as shown in Table 2. Given these sediment yields, beach changes were predicted. In this calculation, however, the reproduction of the gentle slope in the offshore zone was unsuccessful because the contents $\mu_{2}$ and $\mu_{3}$ corresponding to the medium- and coarse-size materials with a large equilibrium slope are high.

Therefore, regarding the riverbed material measured immediately downstream of the Ii-izumi weir, the range of medium-size sand population was assumed to be included in the range of fine-size material,

\begin{tabular}{|c|c|}
\hline Calculation method & $\begin{array}{l}\text { Contour-line-change model considering grain size change } \\
\text { Angular spreading method for irregular waves (Sakai et al., 2006) }\end{array}$ \\
\hline Calculation domain & $\begin{array}{l}\text { Longshore stretch of } 8 \mathrm{~km} \text { between Sakawa River and Ninomiya fishing port on Seisho } \\
\text { coast and cross-shore width of } 2 \mathrm{~km}\end{array}$ \\
\hline Initial bathymetry & Bathymetry measured in 1990 \\
\hline Cases & $\begin{array}{l}\text { Reproduction calculation: } 1947 \text { under natural conditions and } 2007 \\
\text { Case 1: no measures } \\
\text { Case 2: nourishment using coarse-size material }\left(2.0 \times 10^{4} \mathrm{~m}^{3} / \mathrm{yr}\right) \\
\text { Case 3: nourishment using fine-size material }\left(2.0 \times 10^{4} \mathrm{~m}^{3} / \mathrm{yr}\right) \\
\text { Case 4: nourishment using material with mixed grain size }\left(2.0 \times 10^{4} \mathrm{~m}^{3} / \mathrm{yr}\right) \\
\end{array}$ \\
\hline $\begin{array}{l}\text { Incident wave } \\
\text { conditions }\end{array}$ & $\begin{array}{l}\text { Energy-mean waves: wave height } H=0.83 \mathrm{~m} \text {, wave period } T=6.1 \mathrm{~s} \text { and wave direction of } \\
\mathrm{S} 17^{\circ} \mathrm{E}\end{array}$ \\
\hline Sea water level & M.S.L. $\pm 0.0 \mathrm{~m}$ \\
\hline Mesh size & $\Delta x=100 \mathrm{~m}$ \\
\hline Time interval $\Delta t$ & $\Delta t=100 \mathrm{hrs}$ \\
\hline Calculation steps & 87.6 steps/yr \\
\hline Grain size & $\begin{array}{l}\text { Equilibrium slope and content } \\
\begin{array}{ll}\text { Fine-size material (smaller than } 0.25 \mathrm{~mm}) & : \tan \beta=1 / 20 \text { and } \mu_{1}=0.75 \\
\text { Medium-size material }(0.25-2 \mathrm{~mm}) & : \tan \beta=1 / 10 \text { and } \mu_{2}=0.20 \\
\text { Coarse-size material (larger than } 2 \mathrm{~mm}) & : \tan \beta=1 / 7 \text { and } \mu_{3}=0.05 \\
\text { Thickness of exchange layer: } 1 \mathrm{~m} \text { (in slope of } 1 / 30)\end{array}\end{array}$ \\
\hline $\begin{array}{l}\text { Depth distribution of } \\
\text { sediment transport }\end{array}$ & Cubic equation given by Uda and Kawano (1996) \\
\hline Depth of closure & $h_{c}=9 \mathrm{~m}$ \\
\hline Berm height & $h_{R}=3 \mathrm{~m}$ \\
\hline $\begin{array}{l}\text { Coefficient of } \\
\text { sediment transport }\end{array}$ & $\begin{array}{l}K_{x}=\mathrm{A} / \sqrt{d_{50}}, \mathrm{~A}=0.055 K_{x}=0.123 \text { (fine-size material), } K_{x}=0.055 \text { (medium-size material) } \\
\text { and } K_{x}=0.025 \text { (coarse-size material) } \\
\text { Ratio of coefficient of cross-shore sand transport to } K_{x}: K_{y} / K_{x}=0.2 \\
\text { Coefficient by Ozasa and Brampton }(1980): K_{2}=1.62 K_{x}(\tan \beta=1 / 30) \\
\text { Critical slope } 1 / 2 \text { on land and } 1 / 7 \text { on seabed }\end{array}$ \\
\hline Boundary conditions & $\begin{array}{l}\text { Sediment supply from Sakawa River: } 2.0 \times 10^{5} \mathrm{~m}^{3} / \mathrm{yr} \text { before } 1947 \text { and } 1.0 \times 10^{5} \mathrm{~m}^{3} / \mathrm{yr} \text { at } \\
\text { present } \\
\text { Grain size composition } \mu_{1}=0.75, \mu_{2}=0.20 \text { and } \mu_{3}=0.05 \\
q=0 \text { at landward boundary and free boundary at offshore boundary } \\
\text { Sand loss into submarine canyon } 1.0 \times 10^{5} \mathrm{~m}^{3} / \mathrm{yr} \text { under natural conditions }\end{array}$ \\
\hline $\begin{array}{l}\text { Wave transmission } \\
\text { coefficient of } \\
\text { exposed rocks }\end{array}$ & $K_{t}=0.7$ between $x=2.0$ and $4.6 \mathrm{~km}$ \\
\hline
\end{tabular}




\begin{tabular}{|c|c|c|c|}
\hline$d(\mathrm{~mm})$ & & Cont & \\
\hline Coarse gravel $(19<d<75 \mathrm{~mm})$ & 0.07 & \multirow{3}{*}{$\begin{array}{l}\text { Coarse-size material } \\
\mu_{3}=0.37\end{array}$} & $\begin{array}{l}\text { Coarse-size material } \\
\mu_{3}=0.1\end{array}$ \\
\hline Medium gravel $(4.75<d<19 \mathrm{~mm})$ & 0.20 & & \multirow{3}{*}{$\begin{array}{l}\text { Medium-size material } \\
\mu_{2}=0.4\end{array}$} \\
\hline Fine gravel $(2<d<4.75 \mathrm{~mm})$ & 0.10 & & \\
\hline Coarse sand $(0.85<d<2 \mathrm{~mm})$ & 0.15 & \multirow{2}{*}{$\begin{array}{l}\text { Medium-size material } \\
\mu_{2}=0.56\end{array}$} & \\
\hline Medium sand $\quad(0.25<d<0.85 \mathrm{~mm})$ & 0.41 & & \multirow{2}{*}{$\begin{array}{l}\text { Fine-size material } \\
\mu_{1}=0.5\end{array}$} \\
\hline Fine sand $\quad(0.075<d<0.25 \mathrm{~mm})$ & 0.06 & $\begin{array}{l}\text { Fine-size material } \\
\mu_{1}=0.06\end{array}$ & \\
\hline
\end{tabular}

\begin{tabular}{|c|l|c|c|}
\hline \multicolumn{4}{|c|}{ Table 3. Grain size composition, equilibrium slope and contents. } \\
\hline \multicolumn{2}{|c|}{ Grain size } & Equilibrium slope & Content \\
\hline \hline Coarse-size material & Larger than $2 \mathrm{~mm}$ & $1 / 7$ & $\mu_{3}=0.05$ \\
\hline Medium-size material & $0.25-2 \mathrm{~mm}$ & $1 / 10$ & $\mu_{2}=0.20$ \\
\hline Fine-size material & Smaller than $0.25 \mathrm{~mm}$ & $1 / 20$ & $\mu_{1}=0.75$ \\
\hline
\end{tabular}

and fine- and medium-size gravels were assumed to be included in the range of medium-size material. Assuming that $\mu_{1}=0.5, \mu_{2}=0.4$ and $\mu_{3}=0.1$ as shown in Table 2, the gentle slope in the offshore zone was successfully predicted. In contrast, the shoreline recession was underestimated downcoast of the groins because the grain size became excessively coarse. Furthermore, the beach slope near the shoreline between the Sakawa and Morito Rivers is as steep as $1 / 10$, so that almost all fine-size material with a small equilibrium slope was discharged before reaching the submarine canyon offshore of the Morito River. Taking into account the fact that fine-size material is discharged offshore through the steep slope regardless of the volume of coarse-size material, the volume of fine-size sediment was increased while keeping the volumes of medium- and coarse-size materials constant, which contributes to the formation of the profile near the shoreline, resulting in the total sediment yield of $2.0 \times 10^{5} \mathrm{~m}^{3} / \mathrm{yr}$. In other words, sediment yield under the natural conditions was increased from $1.0 \times 10^{5}$ to $2.0 \times 10^{5}$ $\mathrm{m}^{3} / \mathrm{yr}$ and the composition of $\mu_{1}=0.75, \mu_{2}=0.20$ and $\mu_{3}=0.05$ was assumed. Given these conditions, the bathymetry around the Sakawa River mouth under the natural conditions was successfully reproduced. In this case, we assumed that the total sediment yield was reduced by half owing to the effect of the riverbed mining and the construction of a dam since 1947. Finally, the contents of each grain size population are summarized in Table 3. In the prediction of beach changes in recent years, beach nourishment near the mouth of the Morito River was considered as well as the wave transmission coefficient $K_{t}=0.7$ of offshore submerged reef scattered offshore between the Morito River and Ninomiya fishing port.

Under the conditions that sediment with the composition of $\mu_{1}=0.75, \mu_{2}=0.20$ and $\mu_{3}=0.05$ is supplied from the river mouth at a rate of $2.0 \times 10^{5} \mathrm{~m}^{3} / \mathrm{yr}$, and sediment flows out through the eastern boundary at a rate of $2 \times 10^{4} \mathrm{~m}^{3} / \mathrm{yr}$, the dynamically equilibrium beach topography reached after $2.0 \times 10^{5}$ steps (2280 years) is shown in Fig. 5. For comparison, the shoreline in 1947 when the effect of the anthropogenic factors such as the riverbed mining was minimal is also shown in Fig. 5. Because of the abundant sediment supply from the river, the river delta significantly developed so that the shoreline becomes very close to the steep slope offshore of the mouth. The concave shoreline between the river mouth and the submarine canyon offshore of the Morito River in 1947 and the predicted shoreline are in good agreement. In addition, the measured features, i.e., the offshore contours up to a depth of $-10 \mathrm{~m}$ extend smoothly and a steep slope develops offshore of $-10 \mathrm{~m}$ in the submarine canyon, are accurately reproduced. The distribution of longshore sand transport in 1947 when the beach topography was under dynamic equilibrium is also shown in Fig. 5(b). Because of the sand loss toward the offshore zone, longshore sand transport gradually decreases eastward from the river mouth.

The predicted bathymetry in 2007 and the comparison between the measured and predicted shorelines are shown in Fig. 6. Under the reduced longshore sand transport, the effect of the construction of groins superimposed with the effect of beach nourishment at a location downcoast of the Morito River jetty. The predicted and measured shorelines are in good agreement, showing the 
(a) Reproduced bathymetry

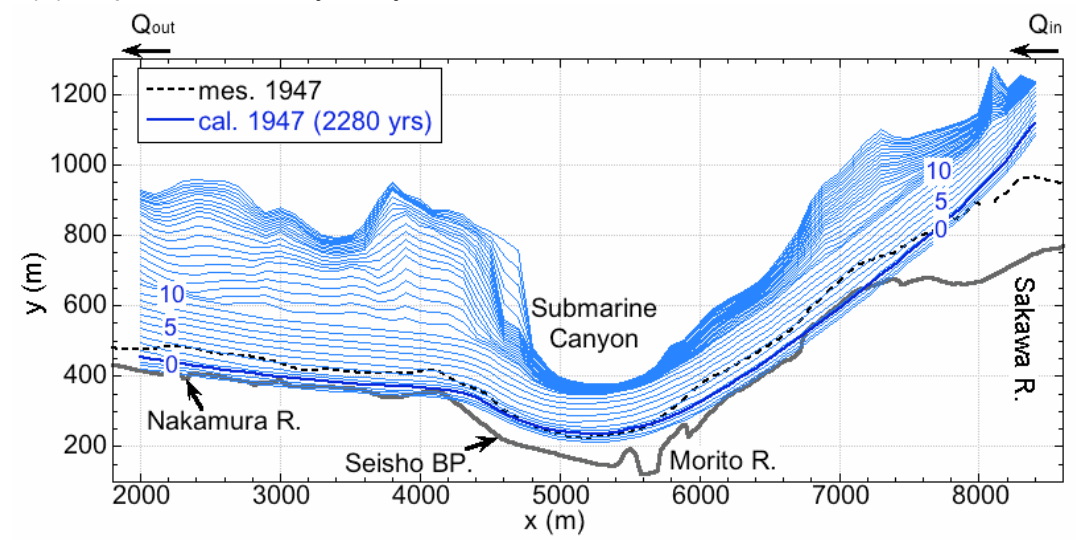

(b) Distribution of longshore sand transport

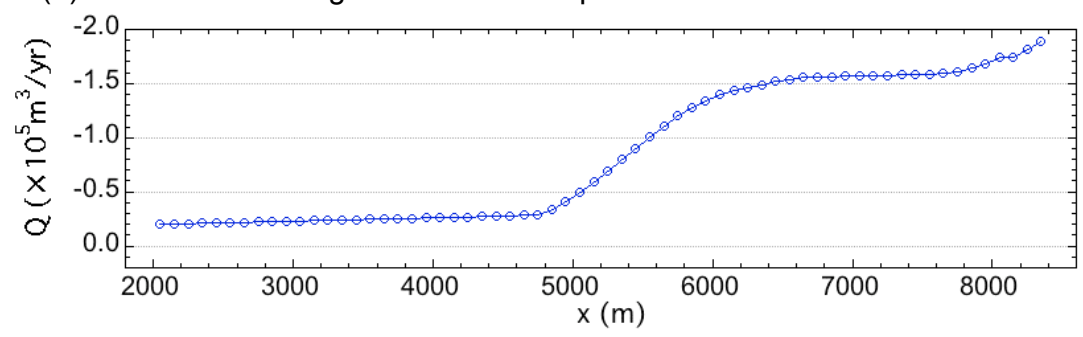

Figure 5. Reproduced bathymetry and distribution of longshore sand transport in 1947.

(a) Reproduced bathymetry

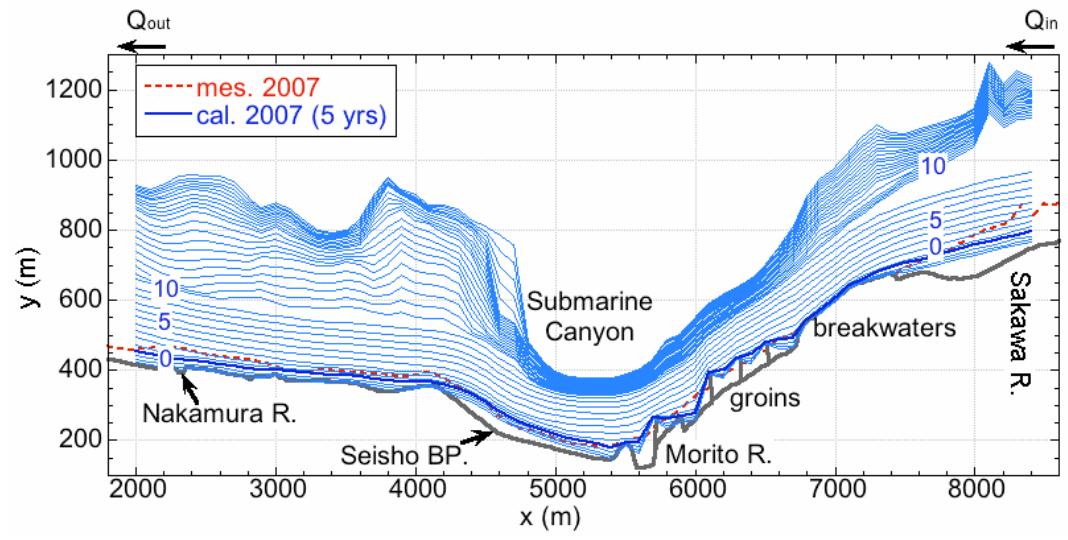

(b) Shoreline changes

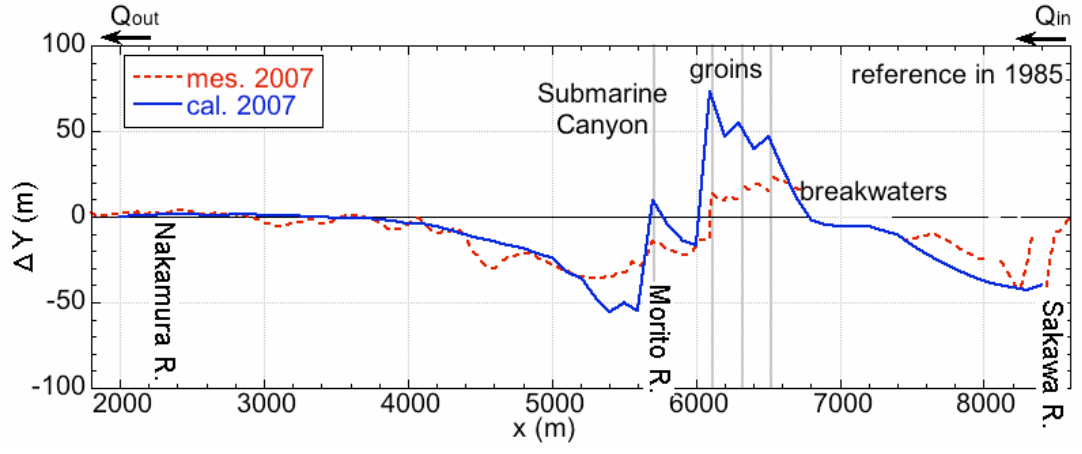

Figure 6. Predicted bathymetry in 2007 and comparison between measured and predicted shorelines. 
(a) Change in longitudinal profile

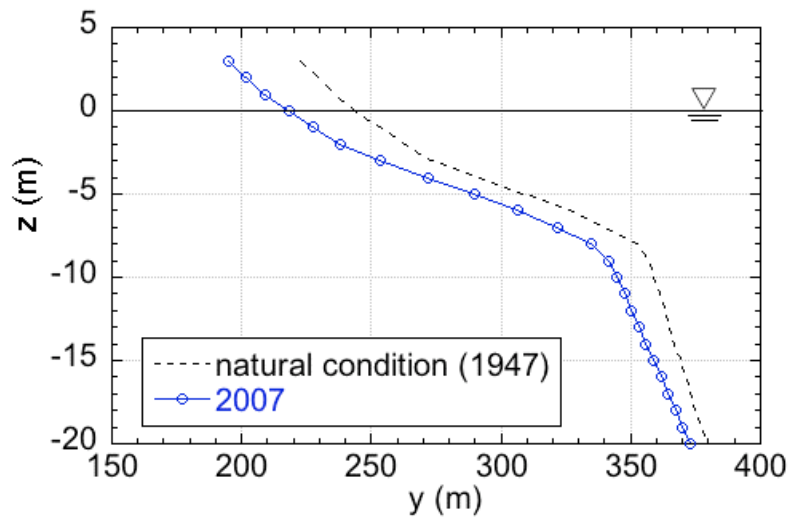

(b) Depth distribution of composition of grain size

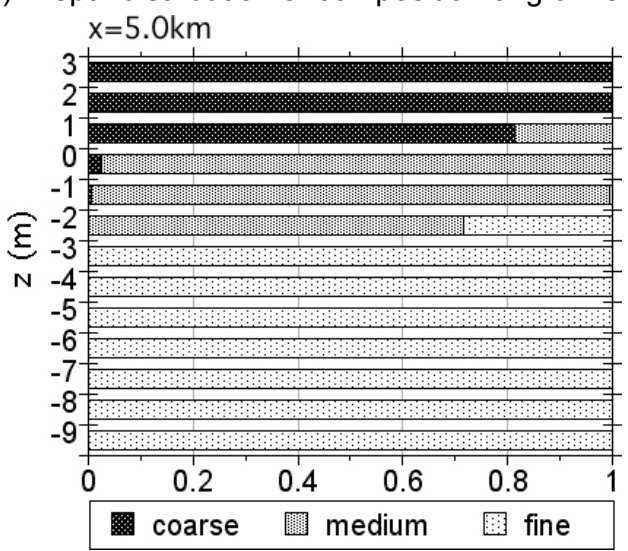

Figure 7. Change in longitudinal profile and depth distribution of composition of grain size in 2007.

capability of reproduction calculation of the beach topography with a sufficient accuracy.

Figures 7(a) and 7(b) show the change in the longitudinal profile and the depth distribution of the content of bed material between 1947 and 2007 along transect $x=5.0 \mathrm{~km}$ across the submarine canyon. Since the sediment supply is significantly reduced compared with that in 1947, the profile retreated in parallel, and coarse-size material is deposited near the shoreline whereas medium-size material is deposited in the offshore zone. This feature is in good agreement with the measured distribution shown in Fig. 3.

\section{COMPARISON OF MEASURES}

Beach changes after ten years from 2007 were predicted when various measures were taken. In Case 1, the shoreline recedes by $20 \mathrm{~m}$ east of the Morito River mouth until the location where $x=4.0$ $\mathrm{km}$ (Fig. 8). In Case 2 in which beach nourishment is carried out using coarse-size material $(d \geq 2 \mathrm{~mm})$, it is deposited near the shoreline because of the large equilibrium slope, and the shoreline markedly

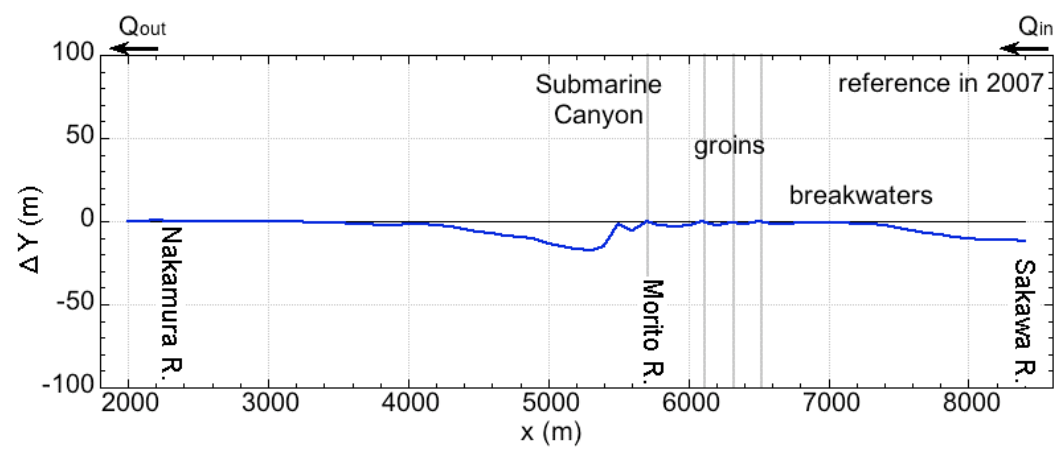

Figure 8. Predicted bathymetry and shoreline changes (Case 1: no measures). 


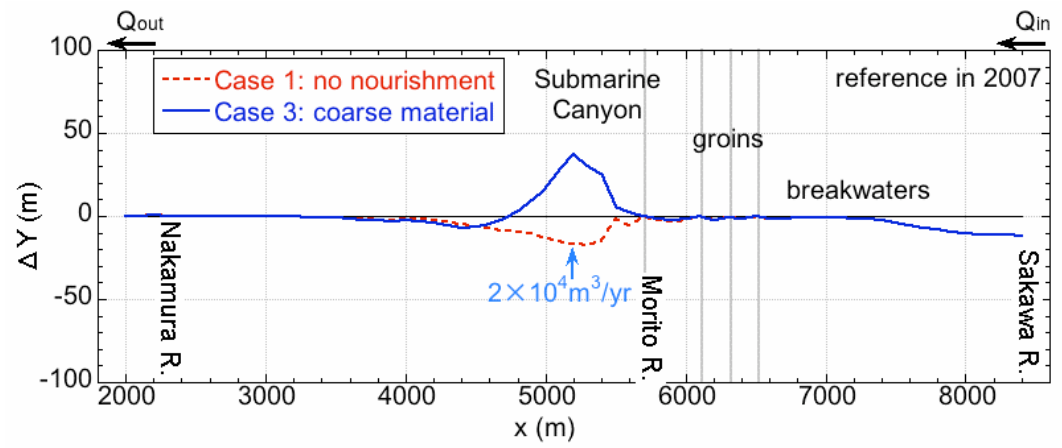

Figure 9. Predicted bathymetry and shoreline changes (Case 2: beach nourishment of coarse-size material).

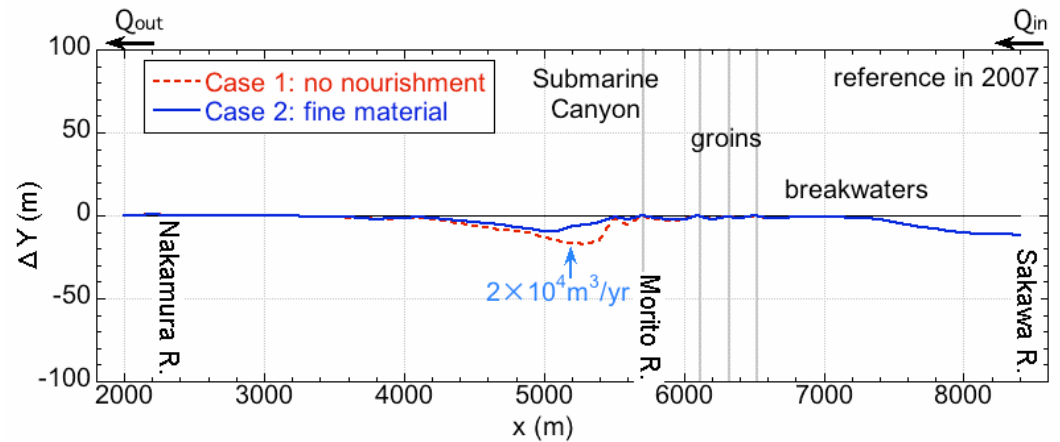

Figure 10. Predicted bathymetry and shoreline changes (Case 3: beach nourishment of fine-size mavterial).

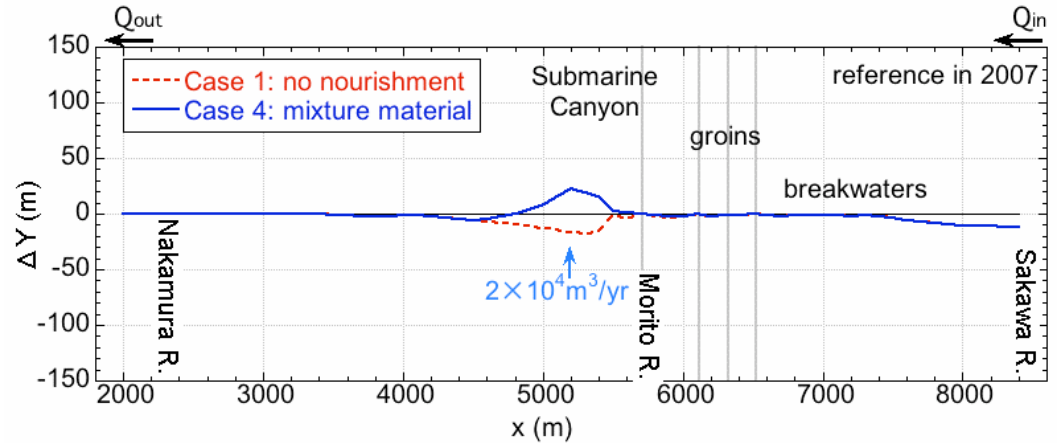

Figure 11. Predicted bathymetry and shoreline changes (Case 4: beach nourishment of material with mixed grain size).

protrudes near the submarine canyon head (Fig. 9). The shoreline advance up to $40 \mathrm{~m}$ is expected because of the continuous beach nourishment for 10 years. In Case 3 in which beach nourishment is carried out using fine-size material, the shoreline slightly advances, i.e., the nourishment has a limited effect (Fig. 10). In contrast, in Case 4 in which beach nourishment of sand composed of both fine- and coarse-size materials is carried out at a rate of $1.0 \times 10^{4} \mathrm{~m}^{3}$, the shoreline advances $20 \mathrm{~m}$, half the shoreline advance in Case 2 (Fig. 11).

Figures 12-15 show the changes in the longitudinal profile along transect $x=5 \mathrm{~km}$ along with the distribution of the beach width. In Case 1 (Fig. 12), the profile near the shoreline markedly retreats with the recession of the contour lines by $20 \mathrm{~m}$, including in the zone deeper than the depth of closure of $-9 \mathrm{~m}$. The reason that the beach profile recedes in the zone deeper than the depth of closure, even though no wave action reaches such a depth, is considered as follows. Along the transect across the submarine canyon head, a dynamically equilibrium profile is considered to have been formed by the sand supply from the Sakawa River and the offshore transport of the equivalent volume of sand via the submarine canyon. However, this initial profile was not maintained because of the decrease in sediment supply.

In Case 2 (Fig. 13), in which beach nourishment using coarse-size material is carried out at the rate of $2.0 \times 10^{4} \mathrm{~m}^{3}$, the profile of a steep slope near the shoreline advances up to a deeper zone, but the 
(a) Longitudinal profile along transect $x=5 \mathrm{~km}$

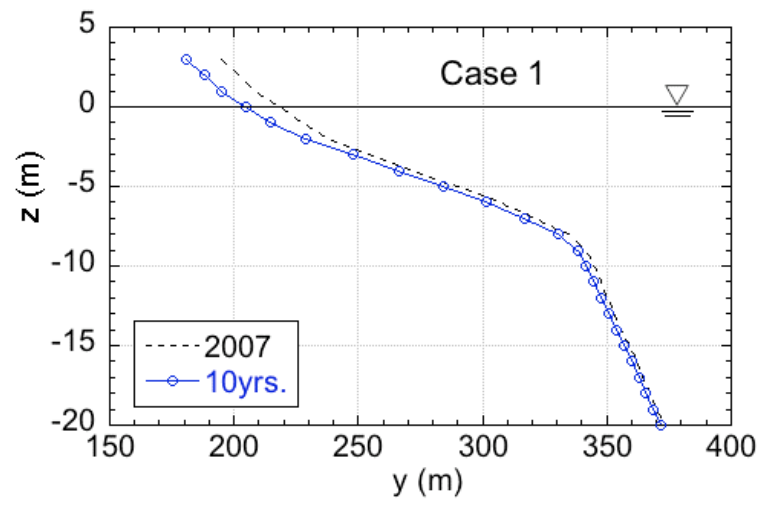

(b) Beach width

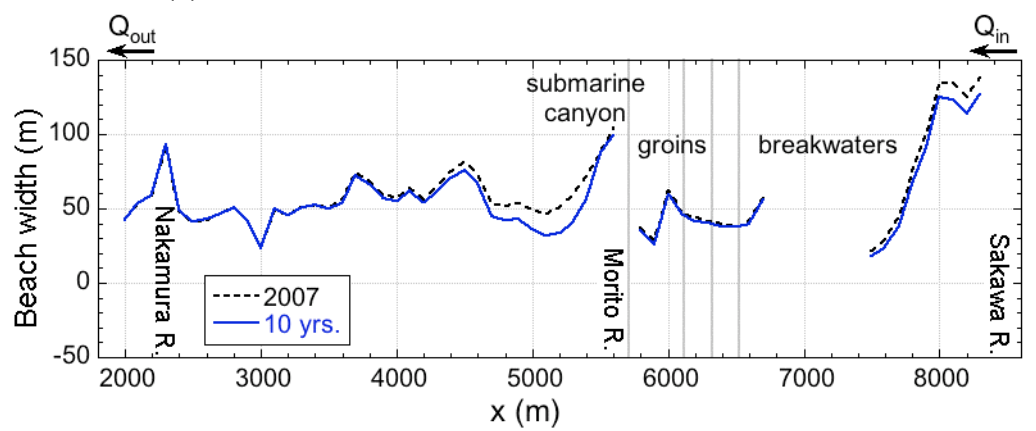

Figure 12. Beach width and changes in longitudinal profile (Case 1: no measures).

(a) Longitudinal profile along transect $x=5 \mathrm{~km}$

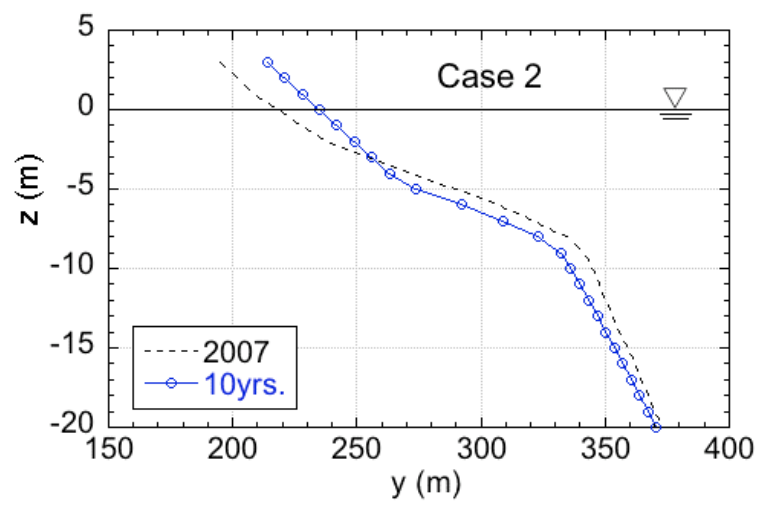

(b) Beach width

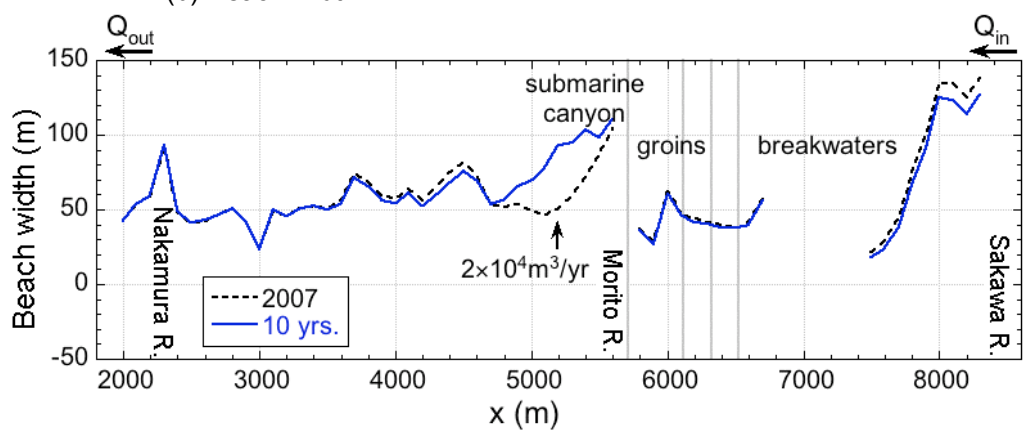

Figure 13. Beach width and changes in longitudinal profile (Case 2: beach nourishment of coarse-size material). 
(a) Longitudinal profile along transect $x=5 \mathrm{~km}$

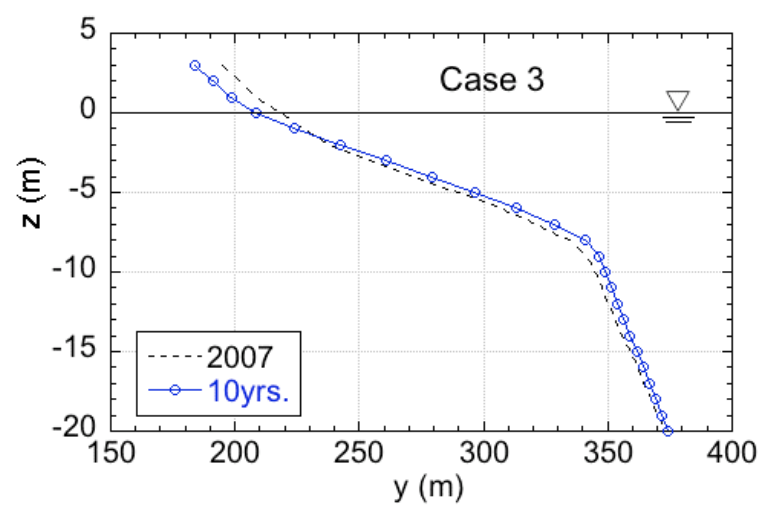

(b) Beach width

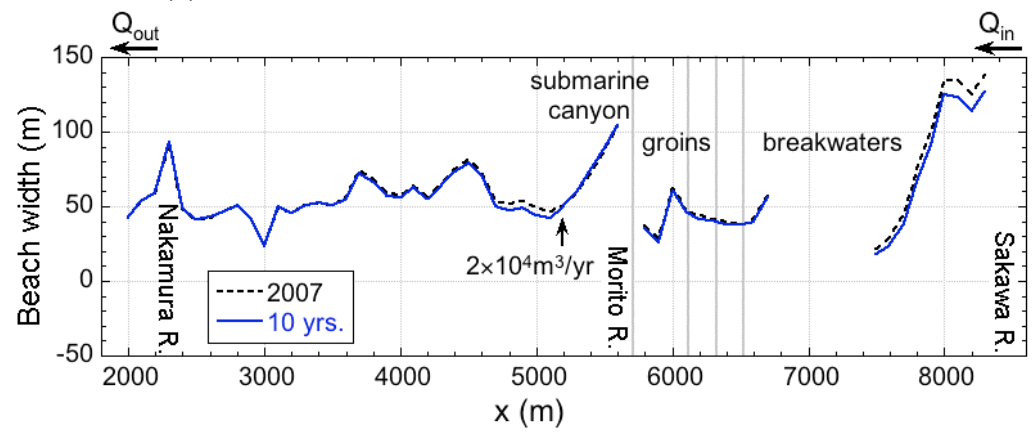

Figure 14. Beach width and changes in longitudinal profile (Case 3: beach nourishment of fine-size material).

(a) Longitudinal profile along transect $x=5 \mathrm{~km}$

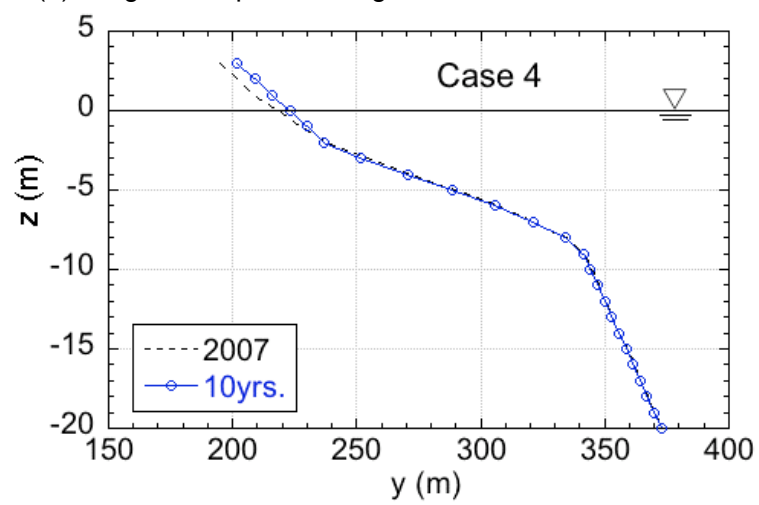

(b) Beach width

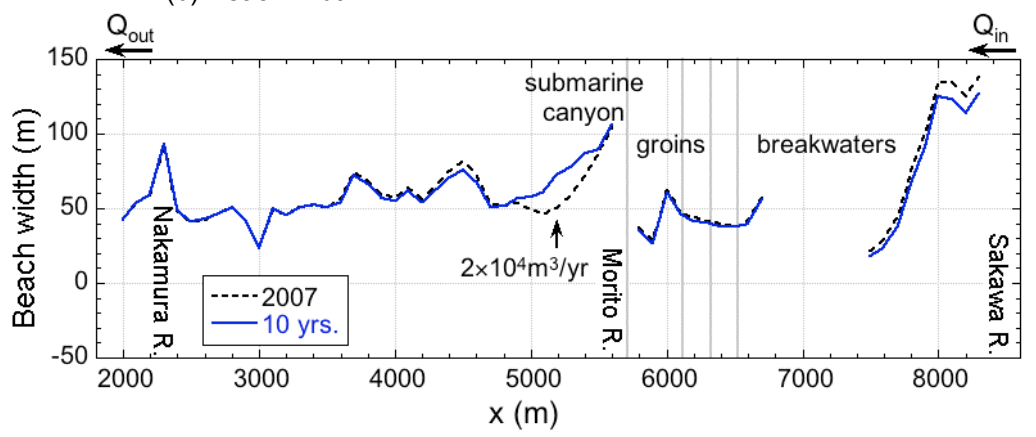

Figure 15. Beach width and changes in longitudinal profile (Case 4: beach nourishment of material with mixed grain size). 
depth of the offshore bed gradually increases because of the shortage of fine-size material. Thus, although the beach width can be widened in the short period, Case 2 is not favorable because of the deepening of the offshore seabed in the long term.

In Case 3 (Fig. 14), the offshore profile advances because of the deposition of fine-size material, even though the shoreline advance is small. Finally, in Case 4 (Fig. 15), the shoreline advances and the decrease in offshore seabed elevation is simultaneously prevented. Thus, the most favorable result obtained is that of Case 4.

\section{CONCLUSIONS}

1. Long-term bathymetric changes of the Seisho coast were predicted using the contour-line-change model, which considers the change in grain size, given the sediment discharge from the Sakawa River and the grain size composition.

2. The bathymetry in 1947 before the decrease in sediment supply and that in 2007 when sediment supply from the river had markedly decreased were accurately reproduced.

3. Beach changes after ten years were predicted including the case that no measures are taken and a comparison of the effect of beach nourishment using fine- and coarse-size materials and their mixture was carried out. When the present conditions are left as they are, the beach width further decreases up to $20 \mathrm{~m}$, increasing the damage potential. Thus, no measures were difficult to adopt.

4. If beach nourishment using coarse-size material is carried out at a rate of $2.0 \times 10^{4} \mathrm{~m}^{3} / \mathrm{yr}$, the shoreline can advance near the head of the submarine canyon, whereas the offshore bed is eroded, because the longitudinal profile near the submarine canyon has been under a dynamically equilibrium condition. When fine-size material is nourished at the same rate, a nourishment effect is expected in the offshore zone while maintaining the present seabed topography, but no recovery of the shoreline is predicted. When a mixture of fine- and coarse-size materials with the same composition is nourished, the shoreline advances, and the decrease in offshore seabed elevation is simultaneously prevented. Thus, the most favorable result is obtained in the case of nourishment using a mixture of fine- and coarse-size materials.

\section{REFERENCES}

Kamphuis, J. W., M. H. Davies, R. B. Narim and O. J. Sayao. 1986. Calculation of littoral sand transport rate, Coastal Engineering, Vol. 10, 1-12.

Kraus, N. C. 1985. Field experiments on vertical mixing of sand in the surf zone, J. Sedimentary Petrology, Vol. 55, 3-14.

Kumada, T., A. Kobayashi, T. Uda and M. Serizawa. 2003. Development of predictive model of shoreline and grain size changes, Coastal Sediments '03, 1-14.

Ozasa, H. and A. H. Brampton. 1980. Model for predicting the shoreline evolution of beaches backed by seawalls, Coastal Eng., Vol. 4, 47-64.

Sakai, K., T. Uda, M. Serizawa, T. Kumada and Y. Kanda. 2006. Model for predicting threedimensional sea bottom topography of statically stable beach, Proc. 30th ICCE, 3184-3196.

Serizawa, M., T. Uda, T. San-nami, K. Furuike and T. Kumada. 2003. Improvement of contour line change model in terms of stabilization mechanism of longitudinal profile, Coastal Sediments '03, $1-15$.

Uda, T. and S. Kawano. 1996. Development of a predictive model of contour line change due to waves, Proc. JSCE, No. 539/ II -35, 121-139. (in Japanese)

Uda, T., T. Kumada and M. Serizawa. 2004. Predictive model of change in longitudinal profile in beach nourishment using sand of mixed grain size, Proc. 29th ICCE, 3378-3390.

Uda, T. and S. Yano. 1987. Beach erosion of Seisho coast facing Sagami Bay, Japan. Geomorphological Union, Vol. 8, 1-19. (in Japanese) 